\title{
OPEN Influence of water washing treatment on Ulva prolifera-derived biochar properties and sorption characteristics of ofloxacin
}

\author{
Chenghu Yang ${ }^{1,2,3}$, Shichao Miao ${ }^{2,3}$ \& Tiejun $\mathrm{Li}^{1 凶}$
}

The influences of water washing treatment on the properties of Ulva prolifera-derived biochar (U.Pbiochar) and its sorption characteristics of ofloxacin (OFL) were investigated. The results showed that the water washing treatment significantly changed the physiochemical structures of U.P-biochars, and improved the sorption capacity of OFL. The sorption capacity of OFL by U.P-biochar was closely dependent on pyrolysis temperature $\left(200-600^{\circ} \mathrm{C}\right.$ ) and equilibrium solution $\mathrm{pH}(3-11)$. Different sorption mechanisms (e.g. cation exchange, electrostatic attraction, $\mathrm{H}$-bond and cationic- $\pi$ and $\pi-\pi$ interactions) were dominant for specific $U . P$-biochars under various $\mathrm{pH}$ regions (acidic, neutral and alkaline). Moreover, the unwashed and washed U.P-biochars prepared at $200^{\circ} \mathrm{C}$ (BC200 and BCW200) showed a higher sorption capacity of $\mathrm{OFL}$ at $\mathrm{pH}=7$. The two-compartment first-order model provided an appropriate description of the sorption kinetics of OFL by BC200 and BCW200 $\left(R^{2}>0.98\right)$, which revealed that the contribution ratios between the fast and slow sorption compartments $\left(f_{\text {fast }} / f_{\text {slowr }} 1.55\right.$ for BC200 and 1.25 for BCW200) reduced after water washing treatment of U.P-biochar. The values of $\mathrm{n}$ for the Freundlich model were less than 1, which demonstrated that the sorption of OFL by BC200 and BCW200 was favourable and nonlinear. Also, the sorption of OFL by BC200 and BCW200 increased with an increase in solution temperature and the sorption process was spontaneous and endothermic. This study provides valuable information for being a primary consideration in the production and application of U.P-biochar.

Antibiotics have received intensive attention for the treatment and prevention of infectious diseases in humans and livestock, especially in high-intensity animal rearing and aquaculture ${ }^{1}$. Meanwhile, antibiotics are indirectly or directly introduced into water and soil through human and animal excreta, untreated wastewater or the discharge of aquaculture products ${ }^{2}$. These actions have resulted in the development and spread of antibiotic resistance, concomitantly causing adverse effects on the ecosystem and human health ${ }^{3,4}$. Statistically, more than 700,000 deaths per year have resulted from antimicrobial resistance since 2014 and it is expected to rise continually to 10 million deaths by $2050^{5}$. Consequently, the management of antibiotics in various environments has drawn great attention.

Numerous methods have been developed to remove antibiotics from water, including sorption, chemical oxidation, photochemical degradation, biological degradation and electrochemical degradation ${ }^{6}$. Among these treatment techniques, sorption has consistently been a superior method because of its relatively low cost, high efficiency and simplicity of operation ${ }^{7,8}$. Besides, sorption is a necessary process controlling the fate and bioavailability of antibiotics in the environment ${ }^{9,10}$. Biochar, a black carbon-rich material obtained from the pyrolysis of organic biomassunder oxygen-limited conditions, has been prevalently recognised as a readily available and environmentally friendly sorbent for contaminant management in water and soil ${ }^{11,12}$. Previous investigations have indicated that biochar could be potentially applied for the sorption of antibiotics from waste water by the combination of multiple mechanisms (e.g. electrostatic attraction, $\pi-\pi$ electron-donor-acceptor interaction and hydrogen bond (H-bond) and hydrophobic interactions) $)^{7,13}$.

It is confirmed that the sorption effects of pollutants by biochar are closely related to its physicochemical properties (e.g. surface area, high cation exchange capacity and surface functional groups), which significantly

${ }^{1}$ Key Laboratory of Sustainable Utilization of Technology Research for Fishery Resource of Zhejiang Province, Zhejiang Marine Fisheries Research Institute, Zhoushan 316021, Zhejiang, People's Republic of China. ${ }^{2}$ Marine and Fishery Institute, Zhejiang Ocean University, Zhoushan 316021, People's Republic of China. ${ }^{3}$ These authors contributed equally: ChenghuYang and Shichao Miao. ${ }^{\circledR}$ email: litiejun19821204@126.com 


\begin{tabular}{|l|l|l|l|l|l|l|l|l|l|l|l|}
\hline Biochars & $\mathbf{C}(\%)$ & $\mathbf{N}(\%)$ & $\mathbf{O}(\%)$ & $\mathbf{H}(\%)$ & $\mathbf{H} / \mathbf{C}$ & $\mathbf{O} / \mathbf{C}$ & $\mathbf{O}+\mathbf{N}) / \mathbf{C}$ & $\mathbf{p H}_{\mathbf{p z c}}$ & $\begin{array}{l}\text { BET surface } \\
\mathbf{a r e a}\left(\mathbf{m}^{2} / \mathbf{g}\right)\end{array}$ & $\begin{array}{l}\text { Total pore } \\
\mathbf{v o l u m e}\left(\mathbf{c m}^{3} \mathbf{g}\right)\end{array}$ & $\begin{array}{l}\text { Average } \\
\text { pore size } \\
(\mathbf{n m})\end{array}$ \\
\hline BC0 & 31.42 & 2.539 & 37.56 & 5.122 & 1.956 & 0.897 & 0.966 & 6.60 & 3.22 & 0.0164 & 20.45 \\
\hline BC200 & 36.31 & 3.538 & 23.24 & 2.463 & 0.814 & 0.480 & 0.564 & 8.18 & 4.65 & 0.0050 & 4.27 \\
\hline BC300 & 37.95 & 3.541 & 21.40 & 2.587 & 0.818 & 0.423 & 0.503 & 8.50 & 19.04 & 0.0143 & 3.00 \\
\hline BC400 & 34.31 & 2.989 & 21.25 & 0.742 & 0.260 & 0.465 & 0.539 & 10.4 & 4.94 & 0.0904 & 73.21 \\
\hline BC500 & 33.65 & 2.618 & 18.53 & 0.631 & 0.225 & 0.413 & 0.480 & 10.9 & 6.06 & 0.0091 & 6.00 \\
\hline BC600 & 32.92 & 2.227 & 14.99 & 0.474 & 0.173 & 0.342 & 0.399 & 11.2 & 13.46 & 0.0067 & 2.33 \\
\hline BCW200 & 61.82 & 5.749 & 23.54 & 5.282 & 1.025 & 0.286 & 0.365 & 6.25 & 4.88 & 0.0189 & 15.52 \\
\hline BCW300 & 64.37 & 5.820 & 21.02 & 5.039 & 0.939 & 0.245 & 0.322 & 6.68 & 26.02 & 0.0582 & 8.95 \\
\hline BCW400 & 65.82 & 5.999 & 20.45 & 2.606 & 0.475 & 0.233 & 0.311 & 7.15 & 31.72 & 0.0685 & 8.64 \\
\hline BCW500 & 61.94 & 4.785 & 19.16 & 2.127 & 0.412 & 0.232 & 0.298 & 10.4 & 135.53 & 0.1920 & 5.66 \\
\hline BCW600 & 61.93 & 4.141 & 15.96 & 1.604 & 0.311 & 0.193 & 0.251 & 10.8 & 257.41 & 0.2830 & 4.40 \\
\hline
\end{tabular}

Table 1. Physiochemical characteristics of U. prolifera and U.P-biochars.

depend on the biomass source and pyrolysis conditions ${ }^{14,15}$. Recently, macroalgae have been used as the precursor for preparing biochars because of their massive abundance and easily acquired nature ${ }^{16}$. Moreover, the conversion of biomass to biochar as one potential end-use will improve the resource utilisation of macroalgae, especially for the 'pest' species (e.g. green tide algae) that exhibit rapid growth and environmental tolerance in eutrophic environments ${ }^{17}$. Ulva prolifera (syn. Enteromorpha prolifera) ${ }^{18}$, a dominant green-tide-forming macroalgae, is distributed diffusely in the intertidal zones of coastal areas around the world ${ }^{19}$. Since its first major occurrence in 2008, the green-tide-forming phenomenon has become an annual event during early summer in the Yellow Sea, causing serious environmental concerns for coastal cities ${ }^{20}$. Prior reports have detailed that biochar produced from U. prolifera successfully exhibited strong sorption capacities for heavy metal, dyes and organic contaminants ${ }^{21,22}$. However, limited information on the sorption characteristics between antibiotics and U. prolifera-derived biochar (U.P-biochar), is available.

Also, the water-soluble materials of biochar, including inorganicchemicals and dissolved organic matter (DOM), would be released once itcontacts aquatic environments. This process may change thesurface properties and porous structures of biochar and subsequently affect its sorption behaviour for contaminants ${ }^{23,24}$. Notably, both positive and negative influences of water washing process on the sorption capacity of biochar have been observed in the diverse reaction systems. For instance, Gai et al. demonstrated that additional sorption sites on the biochar surface might be created to facilitate the sorption of more nitrate $\mathrm{N}$ by removing ash from biochars with water washing treatment ${ }^{25}$. However, Boakye et al. showed that the sorption capacity of Saccharina japonicaderived biochar for crystal violet decreased after water washing, resulting from a decrease in the cation exchange between biochar and dye ${ }^{26}$. Therefore, it is critical to further focus on the roles of water washing treatment on the sorption of contaminants on biochar, which may provide a strategy for the production and potential application of biochar.

The solution $\mathrm{pH}$ is considered one of the main influencing factors in the sorption of antibiotics in water because of the charge distribution on the biochar surface and the ionisation states of antibiotics were different at various $\mathrm{pH}$ ranges. Previous studies showed that the effects of initial $\mathrm{pH}$ on the sorption of antibiotics by biochar were dependent on pyrolysis temperature, attributing to the multiple roles that $\mathrm{pH}$ plays ${ }^{7}$. However, the initial solution $\mathrm{pH}$ might be observably changed in the presence of biochar, which was incapable of indicating the influences of practical $\mathrm{pH}$ values on the sorption between biochar and antibiotics ${ }^{27,28}$. Therefore, understanding the equilibrium $\mathrm{pH}$-dependence of biochar's sorption is crucial for developing efficient remediation approaches.

Ofloxacin (OFL), as one of the major antibiotics consumed in China, has been frequently detected in various environmental media and was chosen as a model antibiotic compound ${ }^{29}$. The primary goal of this work was to evaluate the differences in the properties of washed and unwashed U.P-biochars and those sorption behaviours of OFL, including the pyrolysis temperature and equilibrium solution $\mathrm{pH}$ effects. Meanwhile, multiple sorption mechanisms were discussed based on the structural effects of U.P-biochar and OFL. In addition, the sorption kinetics, sorption isotherms, and thermodynamic analysis were performed to further investigate the sorption characteristics of OFL by U.P-biochar.

\section{Results and discussion}

General properties of U.P-biochar. Table 1 lists the elementary composition and atomic ratio of U.Pbiochar before and after the water washing treatment. First, significant differences in the elemental contents and atomic ratios were observed between $U$. prolifera and its derived biochar, clarifying that biomass properties were changed with limited-oxygen pyrolysis. On the whole, there was no obvious variation in the Content, while the $\mathrm{N}, \mathrm{O}$ and $\mathrm{H}$ contents for U.P-biochar decreased with increasing pyrolysis temperature. The atomic ratio of $\mathrm{H} / \mathrm{C}$ decreased with the pyrolysis temperature, suggesting that the aromaticity of U.P-biochar at a low pyrolysis temperature was significantly lower than that at a high pyrolysis temperature ${ }^{30}$. The decreasing $\mathrm{O} / \mathrm{C}$ ratio indicated an increase in the carbonisation degree and hydrophobicity and the decreased polarity index $[(\mathrm{O}+\mathrm{N}) / \mathrm{C}]$ reflected the reduction of $\mathrm{O}$-containing polar functional groups with increasing pyrolysis temperature ${ }^{31}$. Furthermore, the $\mathrm{C}, \mathrm{H}$ and $\mathrm{N}$ contents increased, while the $\mathrm{O}$ content remained stable with the water washing treat- 


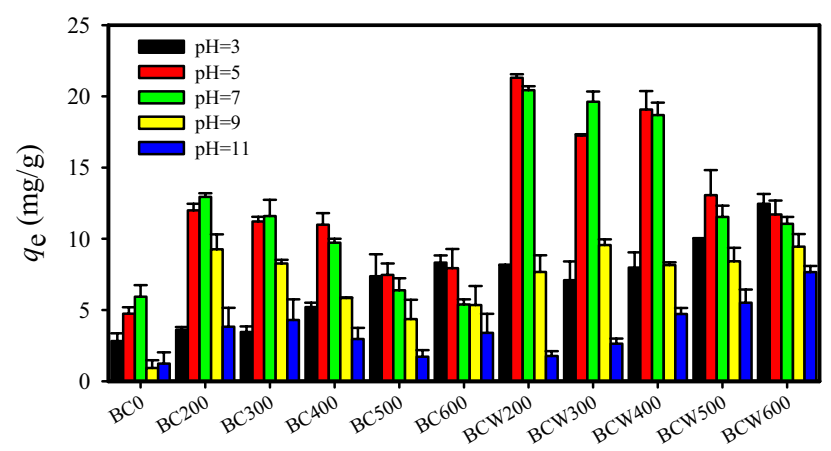

Figure 1. Effects of the pyrolysis temperature and $\mathrm{pH}$ on sorption of OFL by U.P-biochars. [Conditions] $20 \mathrm{~mL}$ of $20 \mathrm{mg} / \mathrm{L}$ OFL; $0.0150 \mathrm{~g}$ of U.P-biochar; 7 days. The experiment was conducted in triplicate.

ment, primarily due tothe ash and DOM of pristine U.P-biochar being removed ${ }^{22}$. The water washing treatment decreased the aromaticity and amount of O-containing functional groups in U.P-biochar according to the higher $\mathrm{H} / \mathrm{C}$ ratio and lower $[(\mathrm{O}+\mathrm{N}) / \mathrm{C}]$ ratio. By contrast, the washed U.P-biochar was a highly carbonised and hydrophobic structure, which was reflected by a lower $\mathrm{O} / \mathrm{C}$ ratio.

The point of zero charge $\left(\mathrm{pH}_{\mathrm{pzc}}\right)$ significantly influences the sorption properties and sorption capacities between biochar and organic pollutants, especially ionizable organic compounds ${ }^{32}$. The $\mathrm{pH}_{\mathrm{pzc}}$ values ranged from 8.18 to 11.2 and 6.25 to 10.81 for the pristine and washed U.P-biochars, respectively (Table 1). The $\mathrm{pH}_{\mathrm{pzc}}$ generally increases with increasing pyrolysis temperature, demonstrating that U.P-biochar obtained at a higher pyrolysis temperature has a strongly basic surface. Meanwhile, the water washing treatment reduced the $\mathrm{pH}_{\mathrm{pzc}}$ of U.P-biochar, suggesting the net surface charges of the pristine and washed biochar were different at the specific $\mathrm{pH}^{33}$. When the solution $\mathrm{pH}$ is lower than $\mathrm{pH}_{\mathrm{pzc}}$, the surface of biochar is positively charged, resulting in a superior ability for the sorption of anionic species. Whereas when the solution $\mathrm{pH}$ is higher than $\mathrm{pH}_{\mathrm{pzc}}$, the biochar surface tends to be negatively charged, leading to an enhancement in cationic species' sorption ability ${ }^{34}$.

The BET surface area of washed U.P-biochars was larger than unwashed U.P-biochars (Table 1), which meaning that more sorption sites of U.P-biochars could be produced with water washing. Furthermore, the BET surface area of washed U.P-biochars increased with increasing pyrolysis temperature. The similar observations had been reported in previous publications ${ }^{35,36}$.

FTIR spectra. The FTIR spectra of pristine and washed U.P-biochars are illustrated in Supplementary Information Fig. S1. The wide band near $3407 \mathrm{~cm}^{-1}$ was ascribed to the stretching of $\mathrm{O}-\mathrm{H}$ in carboxyl and phenol functional groups or the $\mathrm{N}-\mathrm{H}$ symmetric stretching vibration ${ }^{22}$. The characteristic peaks at approximately $2925 \mathrm{~cm}^{-1}$ and $2885 \mathrm{~cm}^{-1}$ were attributed to $\mathrm{C}-\mathrm{H}$ stretching bands associated with aliphatic functional groups. The peak at around $1617 \mathrm{~cm}^{-1}$ was related to aromatic $\mathrm{C}=\mathrm{C}$ or $\mathrm{C}=\mathrm{O}$, while the prominent peaks at approximately $1437 \mathrm{~cm}^{-1}, 1139 \mathrm{~cm}^{-1}$ and $875 \mathrm{~cm}^{-1}$ were assigned to the stretches of $\mathrm{C}-\mathrm{H}_{2}$, aliphatic $\mathrm{C}-\mathrm{O}-\mathrm{C}$ and aromatic C$\mathrm{H}^{25}$. All the FTIR peak intensities of the pristine U.P-biochars exhibited a lower magnitude at a higher pyrolysis temperature, suggesting a decrease in the surface functional groups with an increasing pyrolysis temperature. In addition, significant differences were distinctly observed in the FTIR spectra of the washed and unwashed biochars, confirming that water washing effectively affects the functional groups of U.P-biochar. These bands presented different changes for specific U.P-biochars after the water washing treatment, and the variation trends of U.P-biochars with different pyrolysis temperatures were not completely similar. For instance, all the FTIR peak intensities of BCW200 were lower than those of BC200 except for the peak at approximately $2925 \mathrm{~cm}^{-1}$. A similar variation was also noted between BC300 and BCW300. After the water washing treatment, the peak at $1139 \mathrm{~cm}^{-1}$ became strongly diminished for the U. prolifera-derived biochars prepared at $400{ }^{\circ} \mathrm{C}$ and $500{ }^{\circ} \mathrm{C}$, while other peaks were preserved. Compared with BC600, water washing decreased the intensities of surface functional groups assigned to $1139 \mathrm{~cm}^{-1}$, while three new structures $\left(2925 \mathrm{~cm}^{-1}, 1437 \mathrm{~cm}^{-1}\right.$ and $\left.882 \mathrm{~cm}^{-1}\right)$ were formed in BCW600.

Effects of pyrolysis temperature and $\mathrm{pH}$ on the sorption of OFL by the washed and unwashed U.P-biochars. As shown in Fig. 1, the sorption capacity of U.P-biochar was evidently higher than that of $U$. prolifera, suggesting that limited-oxygen pyrolysis ofbiomass could improve the affinity for OFL. Moreover, the sorption capacities of U.P-biochars for OFL were significantly dependent on the pyrolysis temperature and water washing treatment, which were attributed to the different properties of biochars with various preparation processes. Obviously, the sorption capacity of OFL by the washed U.P-biochar was greater than that by the unwashed U.P-biochar for a specific situation, revealing that the removal of ash and DOM by water washing generated more sorption sites on the washed U.P-biochar surface. Interestingly, the effects of pyrolysis temperature on U.P-biochars sorption of OFL were dependent on the solution $\mathrm{pH}$. The sorption abilities of OFL by both washed and unwashed U.P-biochars increased with the pyrolysis temperature at $\mathrm{pH} 3$, while the opposite trend was observed at $\mathrm{pH} 5$ and 7. The unwashed U.P-biochar sorption capacity of OFL continuously decreased with increasing pyrolysis temperature in the range of 200 to $500{ }^{\circ} \mathrm{C}$ and increased at a pyrolysis temperature of $600{ }^{\circ} \mathrm{C}$ 
at $\mathrm{pH} 9$, while the sorption capacity of washed U.P-biochar gradually increased with the pyrolysis temperature at $\mathrm{pH}$ 11. No apparent regularity was observed for the washed U.P-biochars sorption capacity at $\mathrm{pH} 9$ and the unwashed U.P-biochars at $\mathrm{pH} 11$ for a pyrolysis temperature ranged between 200 and $600^{\circ} \mathrm{C}$. Huang et al. previously stated that the sorption capacity of biochar for OFL increased with the pyrolysis temperature due to the biochars prepared at higher temperatures had more sorption sites ${ }^{7}$. However, another study revealed that the pyrolysis temperature was negatively correlated with the sorption capacity of OFL on biochar, because of the lower oxygen-containing functional groups and the organic distribution phase on the surface of biochar with higher pyrolysis temperature ${ }^{37}$. The aforementioned conflicting findings may be due to the fact that the properties of both the sorbents and the sorbate were different under their respective experimental conditions.

The various influences of $\mathrm{pH}$ on the sorption of OFL by U.P-biochar were also clearly observed. Accordingly, the washed and unwashed U.P-biochars displayed similar $\mathrm{pH}$ dependences of sorption for OFL in each series of U.P-biochars. Thus, we primarily focused on the effects of $\mathrm{pH}$ on the washed U.P-biochars. In detail, with the increase in $\mathrm{pH}$, the sorption capacities of OFL on BCW200, BCW300, BCW400 and BCW500 increased at the beginning and reached a maximal value at asolution $\mathrm{pH}$ of approximately 5 or 7 and then decreased rapidly. It was noted that the sorption capacity of BCW600 continually decreased when the $\mathrm{pH}$ varied 3 to 11 . These variation tendencies in a $\mathrm{pH}$-dependent fashion were mainly due to the fact that the $\mathrm{pH}$ would strikingly shift the surface charge properties of biochar and the species distribution of $\mathrm{OFL}\left(\mathrm{OFL}^{+}, \mathrm{OFL}^{0} \text { and } \mathrm{OFL}^{-}\right)^{38}$. However, the present literature has reported that the sorption of OFL by biochars expressed no significant change for an initial $\mathrm{pH}$ ranging from 3 to $9^{7}$. The following reasons mainly cause the controversy regarding the effects of $\mathrm{pH}$ on the biochars sorption of OFL: (i) the characteristics of biochar from each biomass were unique, resulting in various sorption mechanisms for a further diverse tolerance to $\mathrm{pH}$. (ii) The initial solution $\mathrm{pH}$ could be shifted due to the buffering effect of acidic (carboxyl) and basic (amine) functional groups as well as the alkaline inorganics on the surface of biochars and the process was dependent on various biochars ${ }^{27}$.

Sorption mechanisms. The mechanisms of the above phenomena are discussed for in-depth understanding of the interaction between OFL and U.P-biochars and the washed U.P-biochars were selected as the representatives for this section. The discontinuous variation in the sorption capacity of U.P-biochars suggested that the sorption mechanisms involved in disparate $\mathrm{pH}$ regions were different. Given this, acidic $(\mathrm{pH}=3$ and 5$)$, neutral $(\mathrm{pH}=7)$ and alkaline $(\mathrm{pH}=9$ and 11$)$ were roughly labelled as three various $\mathrm{pH}$ regions.

Acidic region. The solution $\mathrm{pH}\left(3\right.$ and 5) is lower than the $\mathrm{pH}_{\mathrm{pzc}}$ of U.P-biochars (6.25-10.8) and the $\mathrm{p} K_{\mathrm{a} 1}$ (6.10) of OFL, resulting the surface of both sorbent and sorbate are positively charged. Thus, electrostatic repulsion occurred between OFL and the surface of U.P-biochars due to their like charges underacidic conditions ${ }^{34}$. Additionally, the electrostatic repulsion increased with the decrease in $\mathrm{pH}$ and the increase in pyrolysis temperature in this $\mathrm{pH}$ range. However, the substantially higher-than-expected sorption of cationic OFL suggested that cation exchange may have played a key role in the sorption of OFL by U.P-biochars. The sites for cation exchange may have been the oxygen-containing functional groups (such as carboxyl groups) on biochars ${ }^{39}$. A higher temperature could cause less diversity of functional groups on the surface of U.P-biochar, which may in turn affect the ionic exchange during sorption processes. Therefore, the sorption capacity of U.P-biochars would decline theoretically, with an increase in the pyrolysis temperature. Nevertheless, the contrary result was distinctly observed at $\mathrm{pH} 3$, demonstrating that other mechanisms such as cationic $-\pi$ and $\pi-\pi$ interactions also participated in the sorption process ${ }^{40}$. The U.P-biochars formed at a higher pyrolysis temperature contained more aromatic structures, which may have improved the cationic $-\pi$ and $\pi-\pi$ interactions between biochars and cationic OFL.

Neutral region. The content of $\mathrm{OFL}^{+}$decreased to $10.7 \%$, but the $\mathrm{OFL}^{0}$ increased to $84.9 \%$ at a $\mathrm{pH}$ of 7 (Supplementary Information Fig. S2). Thus, the sorption capacity might reduce through the weakening ionic exchange and cationic $-\pi$ interactions between biochar and OFL. However, the sorption capacity of U.P-biochars also exhibited a relatively high level at neutrality, which was probably due to H-bond, $\pi-\pi$ and hydrophobic interactions being involved in the sorption process ${ }^{38}$. Meanwhile, the positive surface charge of U.P-biochars decreased due to the deprotonation effect, leading to significant reduction in the electrostatic repulsion between U.P-biochars and OFL. In addition, according to the characteristicsof U.P-biochars, the contribution of H-bond for biochars decreased with the pyrolysis temperature, while the contribution of $\pi-\pi$ interactions increased with the pyrolysis temperature. Here, the OFL had a good hydrophilicity (i.e. $\log K_{\mathrm{ow}}=-0.39$ ) and the highest sorption values did not all appear at the lowest solubility, which suggested that the sorption of OFL by U.P-biochars was not entirely dependent on the hydrophobic interaction ${ }^{38,39}$.

Alkaline region. The $\pi-\pi$ interaction was also involved in the sorption of OFL by U.P-biochars in the range of $\mathrm{pH}$ at 9-11, which increased with the pyrolysis temperature. The species $\mathrm{OFL}^{-}$is the dominant form in this situation, which accounted for $84.0 \%$ and $98.1 \%$ at $\mathrm{pH} 9$ and 11 , respectively. The electrostatic repulsion was maintained between OFL and U.P-biochars obtained at a pyrolysis temperature $\leq 400{ }^{\circ} \mathrm{C}$, while the electrostatic attraction was generated between OFL and U.P-biochars obtained at a pyrolysis temperature $\geq 500{ }^{\circ} \mathrm{C}$, because these two types of $U . P$-biochars were negatively charged $\left(\leq 400{ }^{\circ} \mathrm{C}\right)$ and positively charged $\left(\geq 500^{\circ} \mathrm{C}\right)$ at $\mathrm{pH} 9^{34}$. The negative charge-assisted $\mathrm{H}$-bond $((-) \mathrm{CAHB})$ may serve as another important mechanism for the sorption of the anionic species of a hydrophilic compoundon a negatively charged carbon surface, which was easily generated as the $\mathrm{H}$-bond donor and $\mathrm{H}$-bond acceptor had comparable $p K_{\mathrm{a}}$ values $^{38}$. The difference between the $p K_{\mathrm{a} 2}(8.28)$ of OFL and the $p K_{\mathrm{a}}$ (strong carboxylic acid $\left(p K_{\mathrm{a}} 5-6.4\right)$, moderate acid/lactone $\left(p K_{\mathrm{a}} 6.4-10.3\right)$ and weak phenolic acid $\left.\left(p K_{\mathrm{a}} 10.3-13\right)\right)^{41}$ of $U . P$-biochars generated at a pyrolysis temperature $\leq 400^{\circ} \mathrm{C}$ was less than 
4, which may have been beneficial to produce (-)CAHB at $\mathrm{pH}$ 9. A U.P-biochar produced at alower pyrolysis temperature had a higher potential for (-)CAHB due to the abundance of its $\mathrm{O}$-containing groups. Thus, the U.P-biochars showed similar sorption capacities due to the joint effects of the electrostatic attraction, electrostatic repulsion, $\pi-\pi$ interaction and $(-) \mathrm{CAHB}$ at $\mathrm{pH}$ 9. The (-)CAHB would be significantly inhibited under strong alkaline conditions due to the excess of hydroxide ions ${ }^{38}$, leading to the sorption capacity of U.P-biochars for OFL being dramatically decreased at $\mathrm{pH} 11$. In addition, both OFL and U.P-biochars became progressively negatively charged with the increase in $\mathrm{pH}$, resulting in the electrostatic repulsion beingsignificantly improved at $\mathrm{pH} 11$. As a consequence, the sorption capacities of U.P-biochars were further reduced under the stronger alkaline condition.

Additionally, the reasons for the promotion of sorption performance of OFL by U.P-biochars after washing treatment could be inferred to these various sorption mechanisms. Firstly, the aromaticity and amount of $\mathrm{O}$-containing functional groups in U.P-biochar reduced after water washing treatment, which showed that the DOM in U.P-biochars contained aromatic substance and abundant functional groups. Thus, the DOM may bind with OFL through cation exchange, $\pi-\pi$ interactions and $\mathrm{H}$-bond, resulting in the competitive sorption with biochar for OFL in water. Secondly, the $\mathrm{pH}_{\mathrm{pzc}}$ of unwashed U.P-biochar was higher than that of washed U.P-biochar, leading to a stronger electrostatic repulsion between OFL and biochar at specific $\mathrm{pH}$ (except $\mathrm{pH}$ 9).

Characterisation of BC200 and BCW200 sorption for OFL. Above results showed that the U.P-biochar produced at apyrolysis temperature of $200{ }^{\circ} \mathrm{C}$ had greater sorption capacity of OFL at pH 7. Thus, BC200 and BCW200 were chosen to further investigate the sorption characteristics of U.P-biochar and OFL by the kinetics, isotherms, thermodynamics at neutrality.

Sorption kinetics. The sorption kinetics is popularly utilised to evaluate the sorption process and sorption mechanism. The sorption kinetic curves of OFL on BC200 and BCW200 showed that the sorption capacity of OFL on U.P-biochar increased with the contact time (Fig. 2a). The dynamic sorption trends of OFL on BC200 and BCW200 could be characterised by three stages including a rapid sorption within the initial $24 \mathrm{~h}$, then a slow sorption, and finally an equilibrium stage at approximately $96 \mathrm{~h}$. This may have been due to the abundance of readily accessible sorption sites on the surfaces of BC200 and BCW200 at the early stage and then the available active sites gradually declined with sorption time, resulting in the slower sorption rate ${ }^{42,43}$. The fitting parameters of the three different kinetic models are presented in Table 2. The pseudo-first-orderand pseudo-second-order models were not suitable to describe the sorption kinetics between OFL and U.P-biochars because of the relatively low correlation coefficients $\left(R^{2}, 0.708-0.865\right)$, which were not consistent with previously obtained results ${ }^{44,45}$. However, the two-compartment first-order model was considered as being the well-fitted model with thehighest correlation coefficients $\left(R^{2}>0.98\right)$. Previous investigations have also reported that the two-compartment first-order model could be employed precisely to explain the sorption of antibiotics (i.e. OFL and tetracycline) on biochar as a two-domain process ${ }^{37,42}$. The values of $k_{\text {fast }}$ and $f_{\text {fast }}$ were higher than those of $k_{\text {slow }}$ and $f_{\text {slow, }}$ revealing that the fast sorption stage was the principal process in our study. The contribution of the fast sorption compartment to the sorption of OFL on BC200 was considerably greater than that on BCW200, which likely accounted for the O-containing functional groups of BC200 being higher than that of BCW200. The interaction between OFL and U.P-biochar is thought to occur via H-bonds and $\pi-\pi$ interactions at neutrality, which may be the possible mechanisms for the rapid sorption of $\mathrm{OFL}^{15}$. The water washing process could decrease the contribution ratios between the fast and slow sorption compartments $\left(f_{\text {fast }} / f_{\text {slow }}\right)$, which was possibly attributed to the removal of ash/minerals. It has been reported that the minerals of biochars played dominant roles in the fast sorption of organic compounds ${ }^{46,47}$. Correspondingly, the values of $k_{\text {slow }}$ and $f_{\text {slow }}$ of BCW200 were larger than those of BC200, which might have been dependent on the pore volume and size of BCW200 being higher than those of BC200 $\left(0.0050 \mathrm{~cm}^{3} / \mathrm{g}\right.$ and $4.27 \mathrm{~nm}$ for BC200, and $0.0189 \mathrm{~cm}^{3} / \mathrm{g}$ and $15.52 \mathrm{~nm}$ for BCW200). Furthermore, the calculated values of $q_{e, \text { cal }}(13.13 \mathrm{mg} / \mathrm{g}$ for BC200 and $21.20 \mathrm{mg} / \mathrm{g}$ for BCW200) from the two-compartment first-order model were in agreement with the $q_{\mathrm{e}, \mathrm{exp}}$ gained by the average of the sorption capacities obtained from 96 to $168 \mathrm{~h}$ (13.07 mg/g for BC200 and $21.57 \mathrm{mg} / \mathrm{g}$ for BCW200) of experimental data, further suggesting that the two-compartment first-order model was suitable for describing the sorption behaviour between OFL and U.P-biochar.

It is widely accepted that the solid-liquid sorption process would be dominated by intraparticle diffusion or liquid film diffusion or both combined ${ }^{48}$. Accordingly, the kinetic sorption data were also analysed with the intra particle diffusion and the liquid film diffusion models for identifying which process controlled the rate of sorption for OFL. As illustrated in Fig. $2 \mathrm{~b}$ and Table 3, the plots of the intraparticle diffusion model did not pass through the origin and the intercepts were positive $(7.52 \mathrm{mg} / \mathrm{g}$ for BC200 and $11.37 \mathrm{mg} / \mathrm{g}$ for BCW200), indicating that the intraparticle diffusion may not have been a primary rate-controlling step in the kinetic process and that sorption occurred mainly on the surface of U.P-biochar ${ }^{48}$. Meanwhile, the results of the liquid film diffusion model showed higher $R^{2}$ values ( 0.930 for BC200 and 0.928 for BCW200) and small intercepts (Fig. 2c and Table 3), conveying that the kinetics of the sorption of OFL on U.P-biochar was principally regulated by the liquid film diffusion mechanism ${ }^{48}$.

Sorption isotherms. Sorption isotherm describes the correlation between the amount of solute sorbed per unit mass of sorbent and the solute concentration in the solution at equilibrium ${ }^{49}$. The sorption isotherms of OFL on BC200 and BCW 200 at $15^{\circ} \mathrm{C}$ and $25{ }^{\circ} \mathrm{C}$ are presented in Fig. 3. It is shown that the sorption capacity of U.P-biochar increased with the increase in the initial concentration of OFL, suggesting that the concentration gradient was the driving force of the sorption ${ }^{22}$. The detailed parameters of the Langmuir and Freundlich models are listed in Table 4. Compared with the Langmuir model, the Freundlich model showed a better representation 

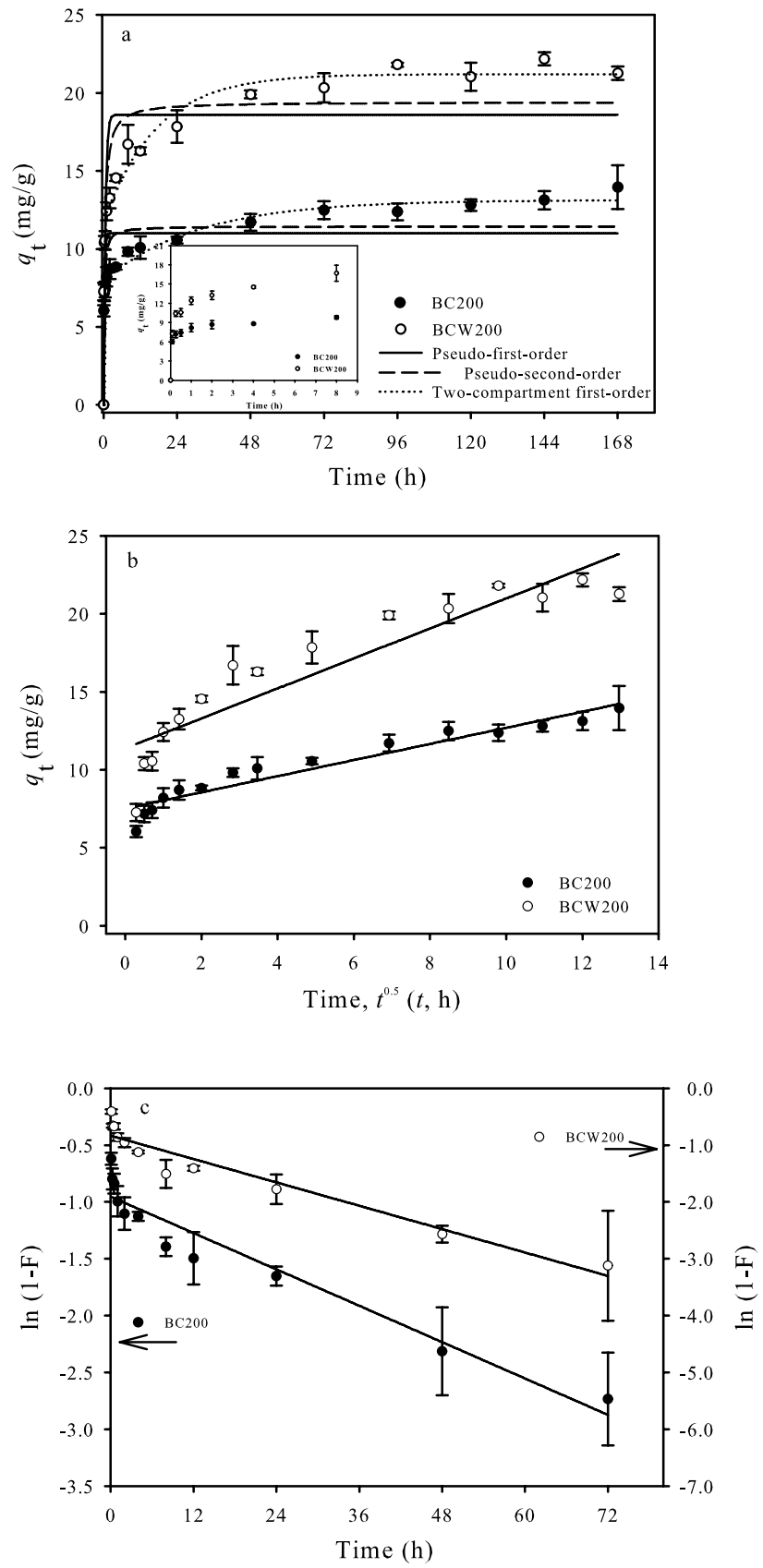

Figure 2. Sorption kinetics of OFL on U. P-biocharsby fitting the pseudo-first-order model, pseudo-secondorder model and two-compartment first-order model (a) intraparticle diffusion model (b) and liquid-film diffusion model (c). [Conditions] $20 \mathrm{~mL}$ of $20 \mathrm{mg} / \mathrm{L}$ OFL; $0.0150 \mathrm{~g}$ of U.P-biochar; $\mathrm{pH}$ of $7.0 \pm 0.2 ; 25^{\circ} \mathrm{C}$. The experiment was conducted in triplicate.

\begin{tabular}{|c|c|c|c|c|c|c|c|c|c|c|c|c|c|}
\hline \multirow[b]{2}{*}{ Biochars } & \multicolumn{3}{|c|}{ Pseudo-first-order model } & \multicolumn{3}{|c|}{ Pseudo-second-order model } & \multicolumn{7}{|c|}{ Two-compartment first-order model } \\
\hline & $q_{\text {e,cal }}$ & $\begin{array}{l}k_{1} \\
\left(h^{-1}\right)\end{array}$ & $R^{2}$ & $\begin{array}{l}q_{\mathrm{e}, \mathrm{cal}} \\
(\mathrm{mg} / \mathrm{g})\end{array}$ & $\begin{array}{l}k_{2} \\
(\mathbf{g} /(\mathbf{m g ~ h}))\end{array}$ & $R^{2}$ & $\begin{array}{l}q_{\mathrm{e}, \mathrm{cal}} \\
(\mathrm{mg} / \mathrm{g})\end{array}$ & $f_{\text {fast }}$ & $\begin{array}{l}k_{\text {fast }} \\
\left(h^{-1}\right)\end{array}$ & $f_{\text {slow }}$ & $\begin{array}{l}k_{\text {slow }} \\
\left(\mathbf{h}^{-1}\right)\end{array}$ & $f_{\text {fast }} / f_{\text {slow }}$ & $R^{2}$ \\
\hline BC200 & 11.00 & 4.03 & 0.708 & 11.45 & 0.48 & 0.812 & 13.13 & 0.61 & 15.93 & 0.39 & 0.03 & 1.55 & 0.984 \\
\hline BCW200 & 18.61 & 1.83 & 0.764 & 19.42 & 0.13 & 0.865 & 21.20 & 0.56 & 10.28 & 0.44 & 0.06 & 1.25 & 0.984 \\
\hline
\end{tabular}

Table 2. The fitting results of the pseudo-first-order model, pseudo-second-order model and twocompartment first-order model. 


\begin{tabular}{|c|c|c|c|c|c|}
\hline \multirow[b]{2}{*}{ Biochars } & \multicolumn{3}{|c|}{$\begin{array}{l}\text { Intra particle diffusion } \\
\text { model }\end{array}$} & \multicolumn{2}{|c|}{$\begin{array}{l}\begin{array}{l}\text { Liquid film } \\
\text { diffusion model }\end{array} \\
\end{array}$} \\
\hline & $\begin{array}{l}\mathrm{A} \\
\mathrm{mg} / \mathrm{g}\end{array}$ & $\begin{array}{l}k_{\mathrm{a}} \\
\mathrm{mg} /\left(\mathrm{g} \mathrm{h}^{0.5}\right)\end{array}$ & $R^{2}$ & $\begin{array}{l}-k_{1 \mathrm{ff}} \\
\left(\mathbf{h}^{-1}\right)\end{array}$ & $R^{2}$ \\
\hline BC200 & 7.52 & 0.52 & \begin{tabular}{|l|}
0.924 \\
\end{tabular} & 0.0267 & 0.930 \\
\hline BCW200 & 0.96 & 11.37 & 0.841 & 0.0343 & 0.928 \\
\hline
\end{tabular}

Table 3. The fitting results of the intraparticle diffusion model and liquid-film diffusion model.
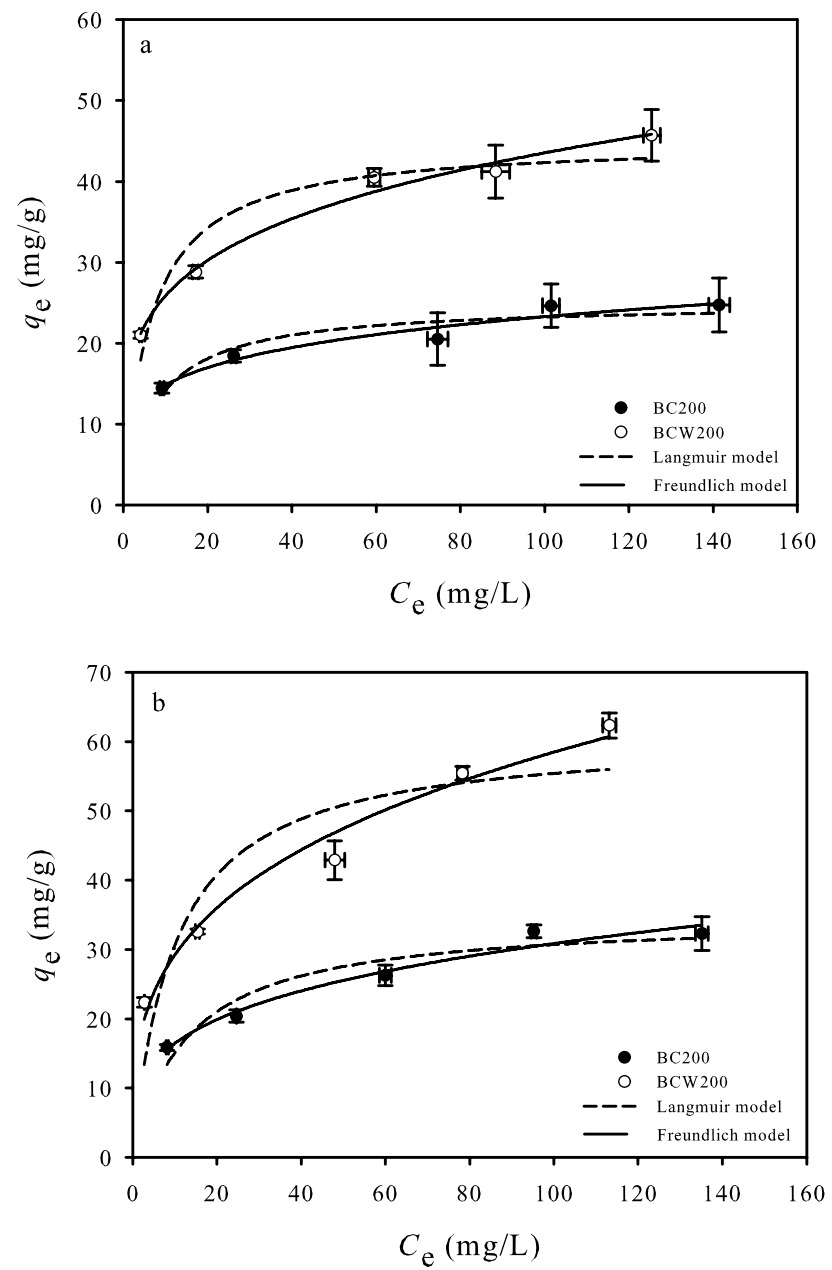

Figure 3. Sorption isotherms of OFL on $\mathrm{BC} 200$ and BCW 200 at $15{ }^{\circ} \mathrm{C}$ (a) and $25^{\circ} \mathrm{C} \mathrm{(b)}$. [Conditions] $20 \mathrm{~mL}$ of 20-160 mg/L OFL; $0.0150 \mathrm{~g}$ of U.P-biochar; $\mathrm{pH}$ of $7.0 \pm 0.2 ; 7$ days. The experiment was conducted in triplicate.

\begin{tabular}{|c|c|c|c|c|c|c|c|c|c|c|}
\hline \multirow[b]{3}{*}{ Temperatures $\left({ }^{\circ} \mathrm{C}\right)$} & \multirow[b]{3}{*}{ Biochars } & \multicolumn{4}{|c|}{ Langmuir model } & \multicolumn{5}{|c|}{ Freundlich model } \\
\hline & & \multirow{2}{*}{$\begin{array}{l}q_{\max } \\
(\mathrm{mg} / \mathrm{g})\end{array}$} & \multirow{2}{*}{$\begin{array}{l}K_{\mathrm{L}} \\
(\mathrm{L} / \mathbf{m g})\end{array}$} & \multirow[b]{2}{*}{$R^{2}$} & \multirow[b]{2}{*}{$R_{\mathrm{L}}$} & \multirow[b]{2}{*}{$\mathbf{n}$} & \multirow{2}{*}{$\begin{array}{l}K_{\mathrm{f}} \\
\left(\mathrm{mg} \mathrm{g}^{-1}\right) /\left(\mathrm{mg} \mathrm{L}^{-1}\right)^{\mathrm{n}}\end{array}$} & \multirow[b]{2}{*}{$R^{2}$} & \multicolumn{2}{|l|}{$K_{\mathrm{d}}(\mathrm{L} / \mathrm{g})$} \\
\hline & & & & & & & & & $C_{\mathrm{e}}=5 \mathrm{mg} / \mathrm{L}$ & $C_{\mathrm{e}}=50 \mathrm{mg} / \mathrm{L}$ \\
\hline \multirow{2}{*}{15} & BC200 & 25.01 & 0.131 & 0.880 & 0.0455 & 0.196 & 9.447 & 0.945 & 2.590 & 0.407 \\
\hline & BCW200 & 44.98 & 0.159 & 0.914 & 0.0378 & 0.227 & 15.341 & 0.989 & 4.418 & 0.744 \\
\hline \multirow{2}{*}{25} & BC200 & 34.71 & 0.077 & 0.901 & 0.0751 & 0.273 & 8.768 & 0.967 & 2.722 & 0.511 \\
\hline & BCW200 & 60.89 & 0.101 & 0.811 & 0.0583 & 0.301 & 14.601 & 0.975 & 4.743 & 0.949 \\
\hline
\end{tabular}

Table 4. Parameters of the sorption isotherms fitted with the Langmuir and Freundlich models. 


\begin{tabular}{|l|l|l|l|l|l|}
\hline Biochars & Temperatures $\left({ }^{\circ} \mathbf{C}\right)$ & $\ln \boldsymbol{K}_{\mathbf{0}}$ & $\boldsymbol{\Delta} \boldsymbol{G}^{\circ}(\mathbf{K J} / \mathbf{m o l})$ & $\boldsymbol{\Delta} \boldsymbol{H}^{\circ}(\mathbf{K J} / \mathbf{m o l})$ & $\Delta \boldsymbol{S}^{\circ}(\mathbf{J} /(\mathbf{m o l} \mathbf{K}))$ \\
\hline \multirow{2}{*}{ BC200 } & 15 & 7.15 & -17.12 & \multirow{2}{*}{10.65} & 96.42 \\
\cline { 2 - 6 } & 25 & 7.30 & -18.09 & & \\
\hline \multirow{2}{*}{ BCW200 } & 15 & 8.08 & -19.35 & \multirow{2}{*}{19.59} & 135.23 \\
\cline { 2 - 5 } & 25 & 8.36 & -20.71 & & \\
\hline
\end{tabular}

Table 5. The thermodynamic parameters of sorption of OFL by BC200 and BCW200.

of the sorption behaviour of OFL on BC200 and BCW200 due to its high correlation coefficients $\left(R^{2}>0.945\right)$, implying that the sorption process could be explained by a multilayer sorption mechanism that occurred on a heterogeneous surface ${ }^{44}$. The values of $\mathrm{n}$ for the Freundlich isotherm were less than 1 , demonstrating that the sorption of OFL on U.P-biochar was favourable. The water washing process could decrease the nonlinear sorption degree of OFL for a given temperature with a higher $n$ value, which was attributed to the higher aromaticity and lower pore size of the sorbent that is commonly related to a more nonlinear isotherm.

The $K_{\mathrm{d}}$ values of OFL for BC200 and BCW200 were estimated from the Freundlich model at two given equilibration concentrations $\left(C_{\mathrm{e}}=5 \mathrm{mg} / \mathrm{L}\right.$ and $\left.50 \mathrm{mg} / \mathrm{L}\right)$. The $K_{\mathrm{d}}$ values decreased with the increase in the concentration of OFL because of the limited high-energy sorption sites on U.P-biochar ${ }^{50}$. However, the findings of Huang et al. showed that the $K_{\mathrm{d}}$ values increased with the initial OFL concentration for the cassava residue-derived biochar prepared at pyrolysis temperatures of $350^{\circ} \mathrm{C}, 650^{\circ} \mathrm{C}$ and $750^{\circ} \mathrm{C}^{7}$, which was likely due to the principal sorption mechanism (such as micropore filling). The $K_{\mathrm{d}}$ of BCW200 was significantly higher than that of BC200, suggesting that the water washing process could enhance the sorption affinity of OFL towards U.P-biochar. Meanwhile, the $q_{\max }$ of BC200 and BWC200 were $25.01 \mathrm{mg} / \mathrm{g}$ and $44.98 \mathrm{mg} / \mathrm{g}$ at $15^{\circ} \mathrm{C}, 34.71 \mathrm{mg} / \mathrm{g}$ and $60.89 \mathrm{mg} / \mathrm{g}$ at $25^{\circ} \mathrm{C}$, respectively. Thus, the findings clearly demonstrated that the sorption of OFL on BC200 and BCW200 became more favourable with increasing temperature. Also, all the values of $R_{\mathrm{L}}$ between 0 and 1 were a sign of the favourable sorption of OFL on U.P-biochar, as a value equal to zeroreveals the reaction is irreversible and $>1$ is unfavourable ${ }^{48}$. Comparing with previous studies, the sorption capacity of BCW200 were higher than those of most of biochars in the previous reports (Supplementary Information Table S2), suggestting that the U.P-biochar might be successfully utilised as an effective sorbent for OFL removal.

Thermodynamic analysis. The values of $K_{\mathrm{d}}$ and $q_{\max }$ varied with the solution temperature (Table 4 ), indicating that the temperature played a vital role in the sorption process. Therefore, the thermodynamic parameters for the sorption of OFL onto BC200 and BCW200 were estimated clearly, which could provide in depth information on the inherent energetic changes during the sorption process. It should be realised that the determination of $\Delta G^{\circ}, \Delta H^{\circ}$, and $\Delta S^{\circ}$ indeed was dependent on the estimate of the $K_{0}$. As shown in Table 5 , the sorption of OFL on BC200 and BCW200 occurred spontaneously due to the negative values of $\Delta G^{\circ 51}$. The values of $\Delta G^{\circ}$ for a given biochar decreased with increasing temperature, suggesting that the sorption became more favourable at higher temperatures. Moreover, the $\Delta G^{\circ}$ values of BCW200 were more negative than those of BC200, which also confirmed that the sorption affinities of OFL on BCW200 were greater than those on BC200. The positive values of $\Delta H^{\circ}$ implied that the sorption of OFL on BC200 and BCW200 was endothermic; therefore, the temperature elevation accelerated the sorption process ${ }^{52}$. The positive values of $\Delta S^{\circ}$ reflected an increase in the disorder and randomness at the solid-liquid interface during the sorption process ${ }^{52}$.

\section{Conclusions}

This study demonstrated that the U.P-biochar properties and the sorption characteristics of OFL varied significantly after water washing treatment. The aromaticity and amount of $\mathrm{O}$-containing functional groups of washed U.P-biochar were lower than those of unwashed U.P-biochar and the water washing treatment reduced the $\mathrm{pH}_{\mathrm{pzc}}$ of U.P-biochar. Furthermore, the washed U.P-biochar showed a much higher sorption capacity of OFL than the unwashed U.P-biochar. The effects of pyrolysis temperature on the U.P-biochar sorption of OFL were significantly dependent on the solution $\mathrm{pH}$ due to different sorption mechanisms (e.g. cation exchange, electrostatic attraction, $\mathrm{H}$-bond, and cationic $-\pi$ and $\pi-\pi$ interactions) involved in diverse $\mathrm{pH}$ regions. In particular, BC200 and BCW200 exhibited a higher sorption capacity of OFL at neutrality. The fast sorption rate of BC200 was higher than that of BCW200 and the ratio of OFL fast and slow sorption fractions decreased after water washing treatment of U.P-biochar. The sorption affinity of BCW200 was greater than that of BC200, and the sorption coefficient increased with lower given equilibration concentration and higher solution temperature. Thermodynamic parameters demonstrated that the sorption of OFL on BC200 and BCW200 was spontaneous and endothermic. It is experimentally concluded that washed U.P-biochar can serve as a low cost and effective sorbent for OFL removal from water, but the selection of the optimal pyrolysis temperature should be based on the actual situation.

\section{Materials and methods}

Chemicals and materials. U. proliferawas acquired from the Xiangshan Xuwen Seaweed Development Co., Ltd. in Zhejiang Province, China. OFL (analytical standard, 99.9\%) was purchased from Aladdin Inc. (Shanghai, China). All chemicals in the experiment were of analytical grade or better and used without further purification. The selected physicochemical properties of OFL are listed in Supplementary Information Table S1. 
Biochar production and characterisation. The preparation of U.P-biochar was detailed in our previous study ${ }^{53}$. The produced biochars are hereafter referred to as BC200, BC300, BC400, BC500 and BC600, where the suffix number represents the pyrolysis temperature; $\mathrm{BC} 0$ is the raw $U$. prolifera biomass. The pristine U.P-biochars were mixed with deionised water and the solid-liquid ratio was 1:100 (w/v). The mixture was shaken with an incubator shaker $\left(180 \mathrm{rpm}, 25^{\circ} \mathrm{C} \pm 1^{\circ} \mathrm{C}\right)$ in the dark for $12 \mathrm{~h}$. Subsequently, the samples were filtered through a $0.45-\mu \mathrm{m}$ pore size membrane under vacuum for separating the washed U.P-biochar. The above process was repeated until the absorption spectra of the filtrate are close to that of deionised water. Finally, the washed U.Pbiochars were dried in an oven at $105^{\circ} \mathrm{C}$ until constant weight and milled to pass through a 100-mesh sieve. The washed U.P-biochars were labelled as BCW200, BCW300, BCW400, BCW500 and BCW600.

The elemental C, N, H and O abundances of U.P-biochar were measured with an elemental analyser (Vario ELIII, Elementar, Germany). The surface areas and porous structures were determined by $\mathrm{N}_{2}$ adsorption at $77 \mathrm{~K}$ using a volumetric gas adsorption instrument (ASAP2460, Micromeritics, USA). The FTIR spectra were qualitatively recorded by a Fourier transform infrared spectrometer (Nicolet iS5, Thermo Fisher, USA) in the range of $400-4000 \mathrm{~cm}^{-1}$. The $\mathrm{pH}_{\mathrm{pzc}}$ was measured as described in a previous study ${ }^{35}$.

Batch sorption experiments. Batch sorption experiments compared the sorption capacities of OFL by the washed and unwashed U.P-biochars for exploring the influences of water washing treatment and assessing the optimal pyrolysis temperature and solution $\mathrm{pH}$. The preliminary experiment showed that the initial solution $\mathrm{pH}$ would be significantly changed by the addition of U.P-biochar and the equilibrium $\mathrm{pH}$ was similar for the specific biochar. Thus, the $\mathrm{pH}$ of the biochar solution was adjusted before mixing with OFL for better understanding the effect of solution $\mathrm{pH}$ on the sorption of OFL by U.P-biochar. Briefly, approximately $0.0150 \mathrm{~g}$ of U.Pbiochar was pre-wetted in a $12 \mathrm{~mL}$ background solution $\left(0.01 \mathrm{~mol} / \mathrm{L} \mathrm{NaCl}\right.$ and $200 \mathrm{mg} / \mathrm{L} \mathrm{NaN}_{3}$ as a biocide) and adjusted to the desired $\mathrm{pH}(3,5,7,9$ and 11 , the standard deviation of each $\mathrm{pH}$ was less than 0.2 .) by $1.0 \mathrm{~mol} / \mathrm{L}$ or $0.1 \mathrm{~mol} / \mathrm{L} \mathrm{HCl}$ and $\mathrm{NaOH}$ and then the biochar solution was shaken $(180 \mathrm{rpm})$ in the dark. This process was repeated 2 times a day until the $\mathrm{pH}$ was stable. The total volumetric amounts of acid and base applied in all practical solutions were less than $200 \mu \mathrm{L}$. After that, the OFL working solutions $(50 \mathrm{mg} / \mathrm{L})$ at the predefined $\mathrm{pH}$ were also prepared by the background solution. Subsequently, $8 \mathrm{~mL}$ of OFL working solution was added to the pretreated U.P-biochar samples with an initial OFL concentration of $20 \mathrm{mg} / \mathrm{L}$. The vials were shaken using a shaking incubator $\left(180 \mathrm{rpm}, 25^{\circ} \mathrm{C} \pm 1{ }^{\circ} \mathrm{C}\right)$ in the dark for 7 days to achieve sorption equilibrium. Then, the samples were filtered through a $0.45-\mu \mathrm{m}$ hydrophilic polyethersulfone membrane filter. Finally, the concentration of OFL in the filtrate was analysed by a UV-visible spectrophotometer (Cary50, Varian, USA) at $287 \mathrm{~nm}$. The filtrate was diluted 10 times by distilled water and the $\mathrm{pH}$ of all samples was adjusted to $7.0 \pm 0.2$ before the OFL was measured. The standard curve and regression equation of OFL are shown in Supplementary Information Fig. S3.

The sorption kinetics of OFL by U.P-biochar was conducted at a neutral $\mathrm{pH}$ of $7.0 \pm 0.2$. Briefly, $8 \mathrm{~mL}$ of OFL working solution $(50 \mathrm{mg} / \mathrm{L})$ was mixed with $12 \mathrm{~mL}$ of pretreated U.P-biochar solution with an initial OFL concentration of $20 \mathrm{mg} / \mathrm{L}$. The mixtures were shaken $\left(180 \mathrm{rpm}, 25^{\circ} \mathrm{C} \pm 1^{\circ} \mathrm{C}\right)$ in the dark and the samples were taken at predetermined time intervals to measure the kinetics. To avoid changing the kinetic sorption system's solid-liquid ratio, triplicate samples under the same conditions were sacrificed at each sampling time point.

The sorption isotherm experiments were also performed using the batch equilibration technique at a solution temperature of $15^{\circ} \mathrm{C} \pm 1{ }^{\circ} \mathrm{C}$ and $25^{\circ} \mathrm{C} \pm 1{ }^{\circ} \mathrm{C}$. Briefly, $8 \mathrm{~mL}$ of OFL working solutions with different concentrations $(50 \mathrm{mg} / \mathrm{L}$ to $400 \mathrm{mg} / \mathrm{L})$ were, respectively, added to $12 \mathrm{~mL}$ of pretreated $U . P$-biochar solution $(\mathrm{pH}=7.0 \pm 0.2)$. The initial concentrations of various OFL ranged from $20 \mathrm{mg} / \mathrm{L}$ to $160 \mathrm{mg} / \mathrm{L}$. Subsequently, the samples were shaken for 7 days to achieve sorption balance and the residual concentrations of OFL were measured. Also, blank controls containing only OFL or biochar were established and all the experiments were run in triplicate.

Data analysis. The Lagergren pseudo-first-ordermodel [Eq. (1)], pseudo-second-order model [Eq. (2)], two-compartment first-order model [Eq. (3)], Weber-Morris Intra particle diffusion model [Eq. (4)] and liquid film diffusion model [Eq. (5)] were devoted to explain the sorption kinetics of OFL by U.P-biochar. And both Langmuir model [Eq. (6)] and Freundlich model [Eq. (7)] were applied to portray the sorption isotherms of OFL by U.P-biochar. Furthermore, the thermodynamic parameters including the Gibbs free energy change, enthalpy change and entropy change were calculated. The data analysis was conduct by SigmaPlot 10 (Systat Software Inc., CA, USA).

The pseudo-first-order model:

$$
\mathrm{q}_{\mathrm{t}}=\mathrm{q}_{\mathrm{e}}\left(1-\mathrm{e}^{-\mathrm{k}_{1} \mathrm{t}}\right)
$$

The pseudo-second-order model:

$$
\mathrm{q}_{\mathrm{t}}=\frac{\mathrm{k}_{2} \mathrm{q}_{\mathrm{e}}^{2} \mathrm{t}}{1+\mathrm{k}_{2} \mathrm{q}_{\mathrm{e}} \mathrm{t}}
$$

where $\mathrm{t}(\mathrm{h})$ is the time for the sorption period; $q_{\mathrm{e}}(\mathrm{mg} / \mathrm{g})$ and $q_{\mathrm{t}}(\mathrm{mg} / \mathrm{g})$ are the sorbed amounts of OFL on U.Pbiochar at equilibrium and at time $t$, respectively; and $k_{1}\left(\mathrm{~h}^{-1}\right)$ and $k_{2}[\mathrm{~g} /(\mathrm{mg} \mathrm{h})]$ are the rate constants of the pseudo-first-order model and pseudo-second-order model ${ }^{54}$.

Two-compartment first-order model:

$$
\mathrm{q}_{\mathrm{t}}=\mathrm{q}_{\mathrm{e}} \mathrm{f}_{\text {fast }}\left(1-\mathrm{e}^{-\mathrm{k}_{\text {fast }} \mathrm{t}}\right)+\mathrm{q}_{\mathrm{e}} \mathrm{f}_{\text {slow }}\left(1-\mathrm{e}^{-\mathrm{k}_{\text {slow }} \mathrm{t}}\right)
$$


where $f_{\text {fast }}$ and $f_{\text {slow }}$ represent the fractions of the two compartments and $k_{\text {fast }}\left(\mathrm{h}^{-1}\right)$ and $k_{\text {slow }}\left(\mathrm{h}^{-1}\right)$ are the rate constants of the two compartments ${ }^{46}$.

Weber-Morris Intraparticle diffusion model:

$$
\mathrm{q}_{\mathrm{t}}=\mathrm{A}+\mathrm{k}_{\mathrm{a}} \mathrm{t}^{0.5}
$$

where $\mathrm{A}(\mathrm{mg} / \mathrm{g})$ is the intercept of the vertical axis; and $k_{\mathrm{a}}\left(\mathrm{mg} /\left(\mathrm{g} \mathrm{h}^{0.5}\right)\right)$ is the overall diffusion constant for sorption $^{54}$.

Liquid film diffusion model:

$$
\ln (1-\mathrm{F})=-\mathrm{k}_{\mathrm{lf}} \mathrm{t}
$$

where $k_{\mathrm{lf}}\left(\mathrm{h}^{-1}\right)$ is the sorption rate constant of the liquid film diffusion model; $\mathrm{F}$ is the fractional achievement of equilibrium at time $\mathrm{t}$ and it is equal to the ratio of $q_{\mathrm{t}}$ to $q_{\mathrm{e}}{ }^{48}$.

Langmuir model:

$$
\mathrm{q}_{\mathrm{e}}=\frac{\mathrm{q}_{\max } \mathrm{K}_{\mathrm{L}} \mathrm{C}_{\mathrm{e}}}{1+\mathrm{K}_{\mathrm{L}} \mathrm{C}_{\mathrm{e}}}
$$

Freundlich model:

$$
q_{\mathrm{e}}=K_{\mathrm{f}} \cdot C_{\mathrm{e}}^{\mathrm{n}}
$$

where $q_{\mathrm{e}}(\mathrm{mg} / \mathrm{g})$ and $q_{\max }(\mathrm{mg} / \mathrm{g})$ are the sorbed amount of OFL on U.P-biochar at equilibrium and the maximum sorption capacity of OFL, respectively; $C_{\mathrm{e}}(\mathrm{mg} / \mathrm{L})$ is the OFL concentration in the aqueous phase at equilibrium; $K_{\mathrm{L}}(\mathrm{L} / \mathrm{mg})$ and $K_{\mathrm{f}}\left(\mathrm{mg} \mathrm{g}^{-1}\right) /\left(\mathrm{mg} \mathrm{L}^{-1}\right)^{\mathrm{n}}$ are the Langmuir and Freundlich sorption coefficients; and $\mathrm{n}$ (unitless) is a constant usually used as an indicator of isotherm nonlinearity. The single point sorption coefficient $\left(K_{\mathrm{d}}, \mathrm{L} /\right.$ $\mathrm{mg}$ ) of OFL on U.P-biochar was calculated with the equation $K_{\mathrm{d}}=q_{\mathrm{e}} / C_{\mathrm{e}}$ at a given equilibrium concentration ${ }^{55}$.

In addition, the separation factor $\left(R_{\mathrm{L}}\right)$ based on the Langmuir model was evaluate by using the [Eq. (8)].

$$
\mathrm{R}_{\mathrm{L}}=\frac{1}{1+\mathrm{K}_{\mathrm{L}} \mathrm{C}_{0}}
$$

where $C_{0}$ is the highest initial OFL concentration $(\mathrm{mg} / \mathrm{L})$. This parameter indicates that the isotherm is unfavourable $\left(R_{\mathrm{L}}>1\right)$, favourable $\left(R_{\mathrm{L}}<1\right)$, linear $\left(R_{\mathrm{L}}=1\right)$, or irreversible $\left(R_{\mathrm{L}}=0\right)^{48}$.

The thermodynamic parameters were analysed by the following [Eqs. (9-10)].

$$
\begin{aligned}
\Delta \mathrm{G}^{\circ} & =-\mathrm{RT} \ln \mathrm{K}_{0} \\
\ln \left[\frac{\mathrm{K}_{0 \mathrm{~T}_{2}}}{\mathrm{~K}_{0 \mathrm{~T}_{1}}}\right] & =-\frac{\Delta \mathrm{H}^{\circ}}{\mathrm{R}}\left[\frac{1}{\mathrm{~T}_{2}}-\frac{1}{\mathrm{~T}_{1}}\right] \\
\Delta \mathrm{G}^{\circ} & =\Delta \mathrm{H}^{\circ}-\mathrm{T} \Delta \mathrm{S}^{\circ}
\end{aligned}
$$

where $K_{0}$ is the equilibrium partition constant, $\Delta G^{\circ}(\mathrm{kJ} / \mathrm{mol})$ is the Gibbs free energy change, $\Delta H^{\circ}(\mathrm{kJ} / \mathrm{mol})$ is the enthalpy change, $\Delta S^{\circ}(\mathrm{kJ} /(\mathrm{mol} \mathrm{K})$ is the standard entropy change, $R(8.314 \mathrm{~J} /(\mathrm{mol} \mathrm{K}))$ is the universal gas constant and $T(\mathrm{~K})$ is the absolute temperature. The thermodynamic constant $\left(K_{0}\right.$; dimensionless) can been valuated by plotting $\ln \left(q_{\mathrm{e}} / C_{\mathrm{e}}\right)$ versus $C_{\mathrm{e}}$ and extrapolating $C_{\mathrm{e}}$ to zero. The value of the intercept is that of $\ln K_{0}{ }^{56}$.

\section{Data availability}

All datasets generated and/or analyzedduring the current study are included in this published article.

Received: 16 October 2020; Accepted: 6 January 2021

Published online: 19 January 2021

\section{References}

1. Kovalakova, P. et al. Occurrence and toxicity of antibiotics in the aquatic environment: a review. Chemosphere 251, 126351 (2020).

2. Riaz, L. et al. Fluoroquinolones (FQs) in the environment: a review on their abundance, sorption and toxicity in soil. Chemosphere 191, 704-720 (2018).

3. Ben, Y. et al. Human health risk assessment of antibiotic resistance associated with antibiotic residues in the environment: a review. Environ. Res. 169, 483-493 (2019).

4. MacFadden, D. R., McGough, S. F., Fisman, D., Santillana, M. \& Brownstein, J. S. Antibiotic resistance increases with local temperature. Nat. Clim. Change 8, 510-514 (2018).

5. O'Neill, J. Tackling Drug-Resistant Infections Globally: Final Report and Recommendations.http://amr-review.org/sites/default/ files/160525_Final\%20paper_with\%20cover.pdf. (2016).

6. Homem, V. \& Santos, L. Degradation and removal methods of antibiotics from aqueous matrices-a review. J. Environ. Manag. 92, 2304-2347 (2011).

7. Huang, P. et al. Effects of metal ions and $\mathrm{pH}$ on ofloxacin sorption to cassava residue-derived biochar. Sci. Total Environ. 616-617, 1384-1391 (2018).

8. Jang, H. M. \& Kan, E. Engineered biochar from agricultural waste for removal of tetracycline in water. Bioresour. Technol. 284, 437-447 (2019).

9. Chen, Z., Xiao, X., Xing, B. \& Chen, B. pH-dependent sorption of sulfonamide antibiotics onto biochars: sorption mechanisms and modeling. Environ. Pollut. 248, 48-56 (2019). 
10. Jia, M. et al. Sorption of sulfamethazine to biochars as affected by dissolved organic matters of different origin. Bioresour. Technol. 248, 36-43 (2018).

11. Abbas, Z. et al. A critical review of mechanisms involved in the adsorption of organic and inorganic contaminants through biochar. Arab. J. Geosci. 11, 448 (2018).

12. Dai, Y., Zhang, N., Xing, C., Cui, Q. \& Sun, Q. The adsorption, regeneration and engineering applications of biochar for removal organic pollutants: a review. Chemosphere 223, 12-27 (2019).

13. Zhao, J. et al. Coating magnetic biochar with humic acid for high efficient removal of fluoroquinolone antibiotics in water. Sci. Total Environ. 688, 1205-1215 (2019).

14. Nguyen, V.-T. et al. Influence of pyrolysis temperature on polycyclic aromatic hydrocarbons production and tetracycline adsorption behavior of biochar derived from spent coffee ground. Bioresour. Technol. 284, 197-203 (2019).

15. Zhang, P., Li, Y., Cao, Y. \& Han, L. Characteristics of tetracycline adsorption by cow manure biochar prepared at different pyrolysis temperatures. Bioresour. Technol. 285, 121348 (2019).

16. Astorgaespaña, M. S., Calistoulloa, N. C. \& Guerrero, S. Baseline concentrations of trace metals in macroalgae from the Strait of Magellan, Chine. B Environ. Contam. Tox. 80, 97-101 (2008).

17. Yu, K. L. et al. Recent developments on algal biochar production and characterization. Bioresour. Technol. 246, $2-11$ (2017).

18. Hayden, H. S. et al. Linnaeus was right all along: Ulva and Enteromorpha are not distinct genera. Eur. J. Phycol. 38, 277-294 (2003).

19. Aguilera-Morales, M., Casas-Valdez, M., Carrillo-Domìnguez, S., González-Acosta, B. \& Pérez-Gil, F. Chemical composition and microbiological assays of marine algae Enteromorpha spp. as a potential food source. J. Food Compos. Anal. 18, 79-88 (2005).

20. Zhang, T. \& Wang, X. Release and microbial degradation of dissolved organic matter (DOM) from the macroalgae Ulva prolifera. Mar. Pollut. Bull. 125, 192-198 (2017).

21. Chen, Y. Y. et al. Characteristics of Enteromorpha prolifera biochars and their adsorption performance and mechanisms for $\mathrm{Cr}(\mathrm{VI})$. Environ. Sci. 38, 3953-3961 (2017) (in Chinese).

22. Qiao, K. et al. Preparation of biochar from Enteromorpha prolifera and its use for the removal of polycyclic aromatic hydrocarbons (PAHs) from aqueous solution. Ecotox. Environ. Safe. 149, 80-87 (2018).

23. Lu, T., Yuan, H., Wang, Y., Huang, H. \& Chen, Y. Characteristic of heavy metals in biochar derived from sewage sludge. J. Mater. Cycles Waste 18, 725-733 (2016).

24. Wu, H., Dong, X. \& Liu, H. Evaluating fluorescent dissolved organic matter released from wetland-plant derived biochar: effects of extracting solutions. Chemosphere 212, 638-644 (2018).

25. Gai, X. et al. Effects of feedstock and pyrolysis temperature on biochar adsorption of ammonium and nitrate. PLoS ONE 9, el13888 (2014).

26. Boakye, P., Tran, H. N., Lee, D. S. \& Woo, S. H. Effect of water washing pretreatment on property and adsorption capacity of macroalgae-derived biochar. J. Environ. Manag. 233, 165-174 (2019).

27. Sewu, D. D., Boakye, P. \& Woo, S. H. Highly efficient adsorption of cationic dye by biochar produced with Korean cabbage waste. Bioresour. Technol. 224, 206-213 (2017).

28. Bai, S. et al. Sorption mechanisms of antibiotic sulfamethazine (SMT) on magnetite-coated biochar: pH-dependence and redox transformation. Chemosphere, 128805 (2020, in press).

29. Zhang, Q. Q., Ying, G. G., Pan, C. G., Liu, Y. S. \& Zhao, J. L. Comprehensive evaluation of antibiotics emission and fate in the river basins of china: source analysis, multimedia modeling, and linkage to bacterial resistance. Environ. Sci. Technol. 49, 6772-6782 (2015).

30. Zhang, K., Mao, J. \& Chen, B. Reconsideration of heterostructures of biochars: morphology, particle size, elemental composition, reactivity and toxicity. Environ. Pollut. 254, 113017 (2019).

31. Chen, Z., Chen, B. \& Chiou, C. T. Fast and slow rates of naphthalene sorption to biochars produced at different temperatures. Environ. Sci. Technol. 46, 11104-11111 (2012).

32. Choudhary, M., Kumar, R. \& Neogi, S. Activated biochar derived from Opuntia ficus-indica for the efficient adsorption of malachite green dye, $\mathrm{Cu}^{+2}$ and $\mathrm{Ni}^{+2}$ from water. J. Hazard. Mater. 392, 122441 (2020).

33. Rahman, M. A. et al. Removal of arsenate from contaminated waters by novel zirconium and zirconium-iron modified biochar. J. Hazard. Mater. 124488 (2020, in press).

34. Divband Hafshejani, L. et al. Removal of nitrate from aqueous solution by modified sugarcane bagasse biochar. Ecol. Eng. 95, 101-111 (2016).

35. Choi, Y.-K. \& Kan, E. Effects of pyrolysis temperature on the physicochemical properties of alfalfa-derived biochar for the adsorption of bisphenol A and sulfamethoxazole in water. Chemosphere 218, 741-748 (2019).

36. Choi, Y.-K. et al. Adsorption behavior of tetracycline onto Spirulina sp. (microalgae)-derived biochars produced at different temperatures. Sci. Total Environ. 710, 136282 (2020).

37. Huang, Q., Wang, P., Zhang, H., Zhang, D. \& Yue, Z. Sorption kinetics of ofloxacin by carbonaceous sorbents with different characteristics. Environ. Chem. 35, 651-657 (2016) ((in Chinese)).

38. Gao, B., Li, P., Yang, R., Li, A. \& Yang, H. Investigation of multiple adsorption mechanisms for efficient removal of ofloxacin from water using lignin-based adsorbents. Sci. rep. 9, 637 (2019).

39. Peng, H. et al. Adsorption of ofloxacin on carbon nanotubes: solubility, $\mathrm{pH}$ and cosolvent effects. J. Hazard. Mater. 211-212, 342-348 (2012).

40. Zhao, Q. et al. Cation-Pi Interaction: a key force for sorption of fluoroquinolone antibiotics on pyrogenic carbonaceous materials. Environ. Sci. Technol. 51, 13659-13667 (2017).

41. Mandal, A., Singh, N. \& Purakayastha, T. J. Characterization of pesticide sorption behaviour of slow pyrolysis biochars as low cost adsorbent for atrazine and imidacloprid removal. Sci. Total Environ. 577, 376-385 (2017).

42. Jang, H. M., Yoo, S., Choi, Y.-K., Park, S. \& Kan, E. Adsorption isotherm, kinetic modeling and mechanism of tetracycline on Pinus taeda-derived activated biochar. Bioresour. Technol. 259, 24-31 (2018).

43. Li, X.-Y. et al. Hierarchical porous activated biochar derived from marine macroalgae wastes (Enteromorpha prolifera): facile synthesis and its application on Methylene Blue removal. RSC Adv. 8, 29237-29247 (2018).

44. Kong, Q., He, X., Shu, L. \& Miao, M. S. Ofloxacin adsorption by activated carbon derived from luffa sponge: kinetic, isotherm, and thermodynamic analyses. Process Saf. Environ. Prot. 112, 254-264 (2017).

45. Zhu, C., Lang, Y., Liu, B. \& Zhao, H. Ofloxacin adsorption on chitosan/biochar composite: kinetics, isotherms, and effects of solution chemistry. Polycyclic Aromat. Compd. 39, 287-297 (2019).

46. Chen, J., Zhang, D., Zhang, H., Ghosh, S. \& Pan, B. Fast and slow adsorption of carbamazepine on biochar as affected by carbon structure and mineral composition. Sci. Total Environ. 579, 598-605 (2017).

47. Rosales, E., Meijide, J., Pazos, M. \& Sanromán, M. A. Challenges and recent advances in biochar as low-cost biosorbent: from batch assays to continuous-flow systems. Bioresour. Technol. 246, 176-192 (2017).

48. Zhou, Y. et al. Modification of biochar derived from sawdust and its application in removal of tetracycline and copper from aqueous solution: adsorption mechanism and modelling. Bioresour. Technol. 245, 266-273 (2017).

49. Ding, X., Chen, H., Yang, Q., Wei, J. \& Wei, D. Effect of sludge property on the synthesis, characterization and sorption performance of sludge-based biochar. Bioresour. Technol. Rep. 7, 100204 (2019). 
50. Yang, C. H., Liu, Y. Z., Cen, Q. L., Zhu, Y. X. \& Zhang, Y. Insight into the heterogeneous adsorption of humic acid fluorescent components on multi-walled carbon nanotubes by excitation-emission matrix and parallel factor analysis. Ecotox. Environ. Safe. 148, 194-200 (2018).

51. Yao, X. et al. Magnetic activated biochar nanocomposites derived from wakame and its application in methylene blue adsorption. Bioresour. Technol. 302, 122842 (2020).

52. Liu, X., Shen, F., Smith, R. L. \& Qi, X. Black liquor-derived calcium-activated biochar for recovery of phosphate from aqueous solutions. Bioresour. Technol. 294, 122198 (2019).

53. Yang, C. H. et al. Characterization of fluorescent dissolved organic matter from green macroalgae (Ulva prolifera)-derived biochar by excitation-emission matrix combined with parallel factor and self-organizing maps analyses. Bioresour. Technol. 287, 121471 (2019).

54. Wang, X. et al. Sorption of peat humic acids to multi-walled carbon nanotubes. Environ. Sci. Technol. 45, 9276-9283 (2011).

55. Wang, F., Yao, J., Chen, H., Yi, Z. \& Xing, B. Sorption of humic acid to functionalized multi-walled carbon nanotubes. Environ. Pollut. 180, 1-6 (2013)

56. Khan, A. A. \& Singh, R. P. Adsorption thermodynamics of carbofuran on $\mathrm{Sn}$ (IV) arsenosilicate in $\mathrm{H}^{+}, \mathrm{Na}^{+}$and $\mathrm{Ca}^{2+}$ forms. Colloids Surfaces 24, 33-42 (1987).

\section{Acknowledgements}

This work was supported by the National Natural Science Foundation of China (No. 31800430); the Zhoushan Science and Technology Plan Project (No. 2018C31079) and the PhD Research Startup Foundation of Marine Fisheries Research Institute of Zhejiang (No. 20170002).

\section{Authors contributions}

C.Y.: methodology, investigation, data curation, formal analysis, funding acquisition, writing-original draft. S.M.: data curation, visualization, methodology, writing-original draft. T.L.: investigation, data curation, methodology, supervision, writing-reviewing and editing.

\section{Competing interests}

The authors declare no competing interests.

\section{Additional information}

Supplementary Information The online version contains supplementary material available at https://doi. org/10.1038/s41598-021-81314-4.

Correspondence and requests for materials should be addressed to T.L.

Reprints and permissions information is available at www.nature.com/reprints.

Publisher's note Springer Nature remains neutral with regard to jurisdictional claims in published maps and institutional affiliations.

(c) (1) Open Access This article is licensed under a Creative Commons Attribution 4.0 International License, which permits use, sharing, adaptation, distribution and reproduction in any medium or format, as long as you give appropriate credit to the original author(s) and the source, provide a link to the Creative Commons licence, and indicate if changes were made. The images or other third party material in this article are included in the article's Creative Commons licence, unless indicated otherwise in a credit line to the material. If material is not included in the article's Creative Commons licence and your intended use is not permitted by statutory regulation or exceeds the permitted use, you will need to obtain permission directly from the copyright holder. To view a copy of this licence, visit http://creativecommons.org/licenses/by/4.0/.

(C) The Author(s) 2021 